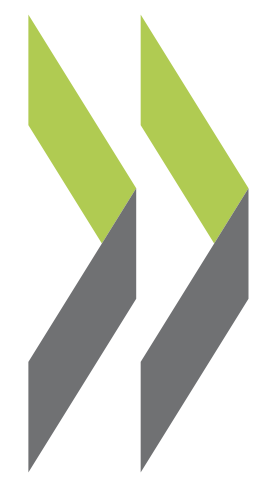

CELE Exchange, Centre for Effective Learning Environments $2011 / 05$

\title{
Ireland's Generic Repeat Design Schools Programme
}

\section{Tony Sheppard}

https://dx.doi.org/10.1787/5kg5c8d54wwh-en 


\section{Ireland's generic repeat design schools programme}

By Tony Sheppard, Department of Education and Science, Ireland

The Irish Department of Education and Skills (DoE) is strongly committed to energy efficiency and to reducing $\mathrm{CO}_{2}$ by developing and implementing energy level ceilings in relation to school design that aim to remain below half of the accepted good practice in the field. This approach works within normal departmental budgetary limits to create school buildings that are breaking ground for building designers.

\section{INTRODUCTION}

\section{Practical simplicity}

The DoE's Planning and Building Unit is now developing low-energy educational buildings with the help of generic repeat design (GRD). This is a programme delivering many primary schools, not just a single demonstration prototype building. To minimise risk on so many projects, it brings together proven-in-use technologies. It is significant because of the practical simplicity of its low energy design and repeatability on sites with varied orientations.

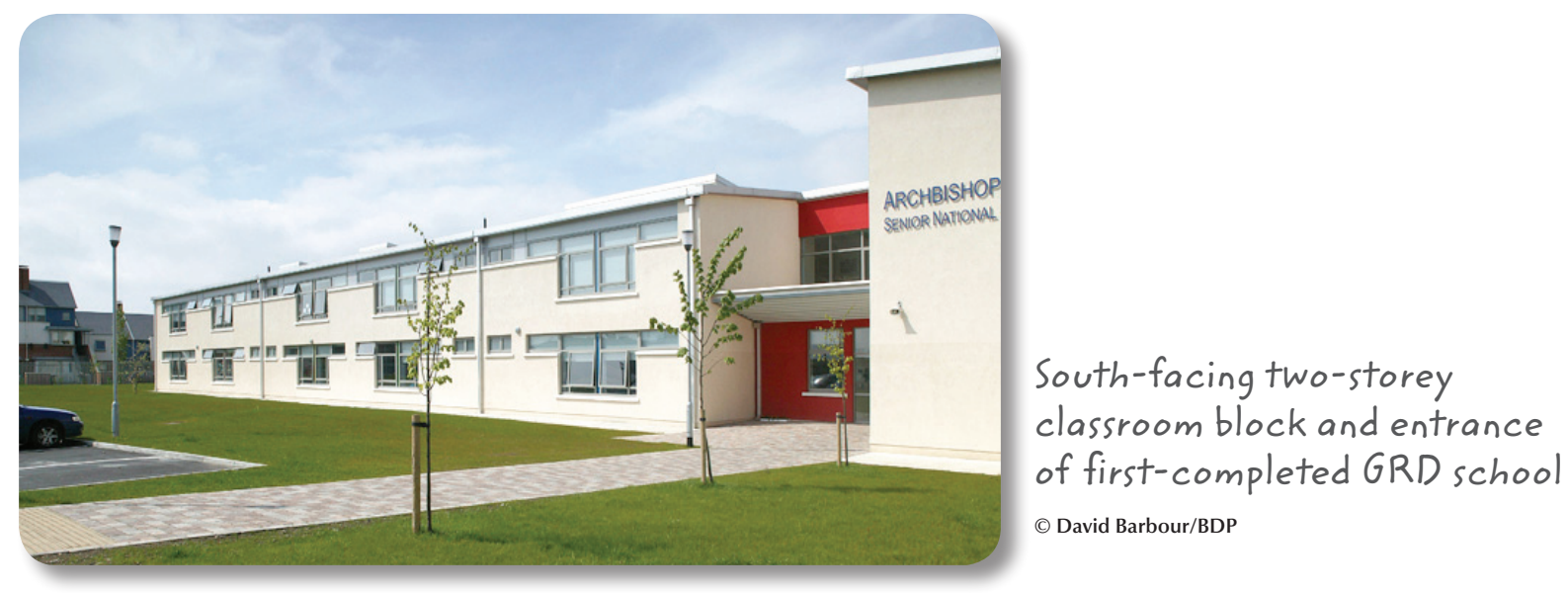

\section{Precedent}

There are clear precedents in Ireland for the use of highly refined standard school plans as part of the government's response to the demands of providing accommodation for large numbers of pupils. The GRD has evolved this procurement method with complete superstructure tender packages available.

\section{Previous research}

Given the requirement to minimise risk on multiple projects, the GRD brings together all currently available proven and tested-in-use technologies. 


\section{ARCHITECTURAL RESPONSE}

\section{Compactness}

The footprint of the two-storey solution offers increased benefits in its compactness, better landuse, reduced building envelope and ability to extend. It contributes to ease of management, better supervision, security and sense of connection between spaces.

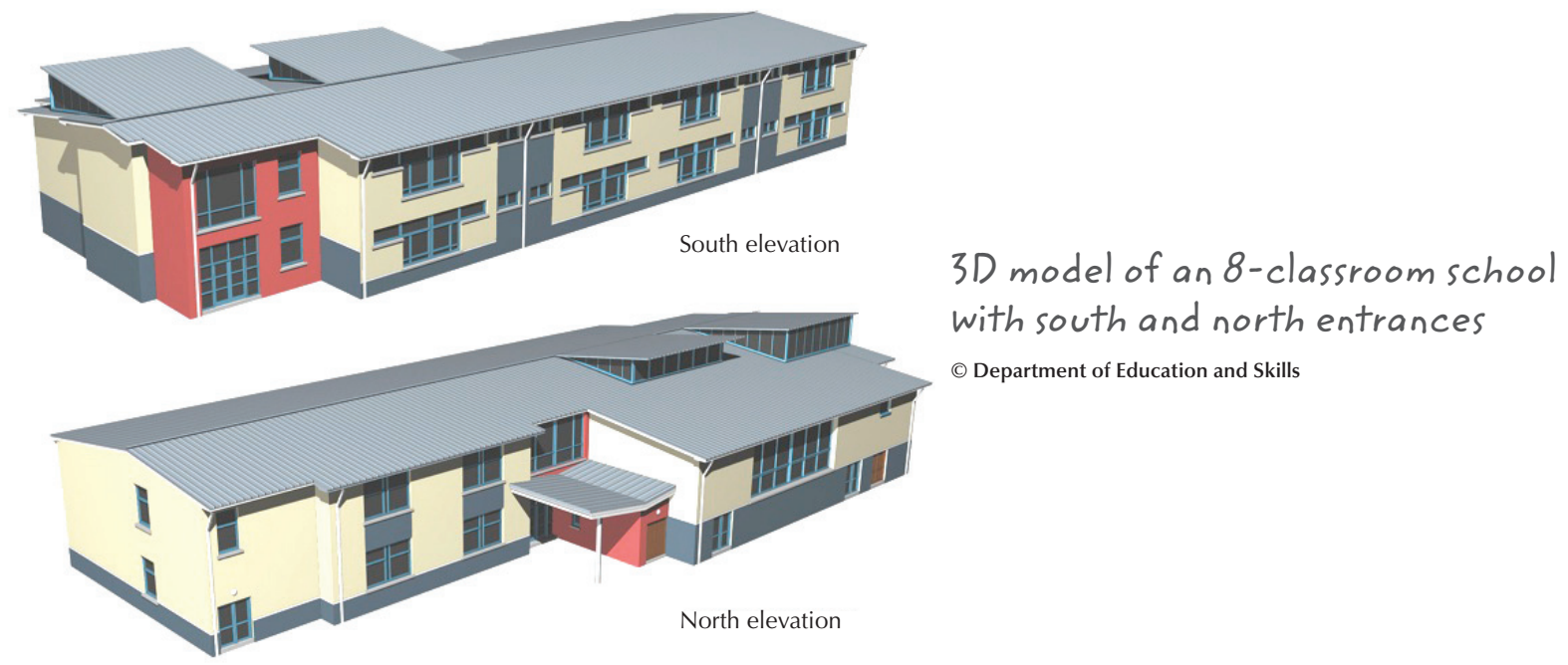

\section{Double-height entrance space}

This is the single most effective organising element in the building, facilitating the generic entrances at either end. It contributes to internal orientation and clear way-finding, a critical need with the integration of special needs pupils. Views to and from the upper-level balcony corridor into the hall give a sense of transparency, visual connection and passive supervision. The atrium with stairs rising to the upper level emphasises unity within the entire school as a "children's house" and reflects the progression of children through school age years.

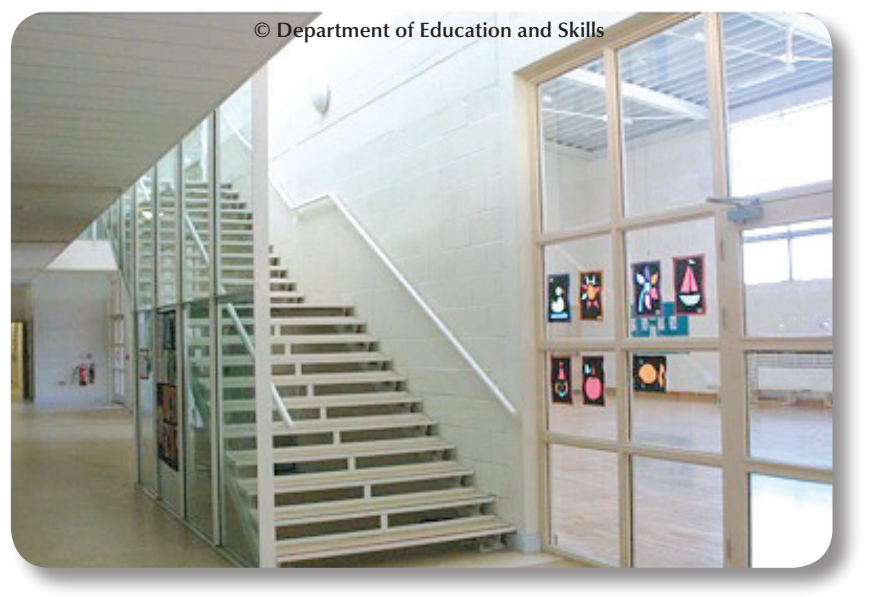

Double-height entrance atrium with stairs to first floor and glazed screen to school hall

\section{Materials}

All building materials and forms of construction were selected on the basis of a whole life-cycle analysis, optimising ease of build, sustainable products, durability and low-maintenance. 


\section{Extendibility}

The 8-classroom school acts as a core containing all ancillary spaces, including a school hall, and allows for extending up to 12 or 16 classrooms. By locating fire stairs at the corridor ends, it is possible to add further extensions in two directions.

\section{Security}

With child safety as a key criterion, passive elements include a prominent entrance to give clear direction, with a draught lobby enabling secure vetting of visitors. Within the school, passive supervision is enhanced by the central atrium and glazed screens.

\section{The acoustic environment}

A good acoustic environment is provided in all spaces, which is essential for the integration of special educational needs pupils.

\section{THE BENEFITS OF A GRD}

The strong points of the GRD model are as follows:

- A fully considered educational model.

- Extendibility and future-proofing potential of the initial core school.

- Timeline savings through the application of an off-the-shelf solution.

- Reduced professional fees on repeat sites.

- Improved internal environments.

- Reduced cost-in-use, whole life cycle and maintenance costs.

- Greater cost certainty in budget projection and planning of schools' capital programme.

\section{PASSIVE SOLAR DESIGN}

\section{Key principles}

- A larger area of glazing should face towards the sun rather than away from it.

- The orientation of the sun-facing windows should take into account the short operating day of a primary school, i.e. $9.00 \mathrm{am}$ to $3.00 \mathrm{pm}$, and that most heating energy is needed during the early stages of the day.

- Rooms that are operated at a cooler temperature should face away from the sun as they do not require as much heating.

Ground floor plan: south and east facing classrooms. Alternative south and north entrances.

(c) Department of Education and Skills

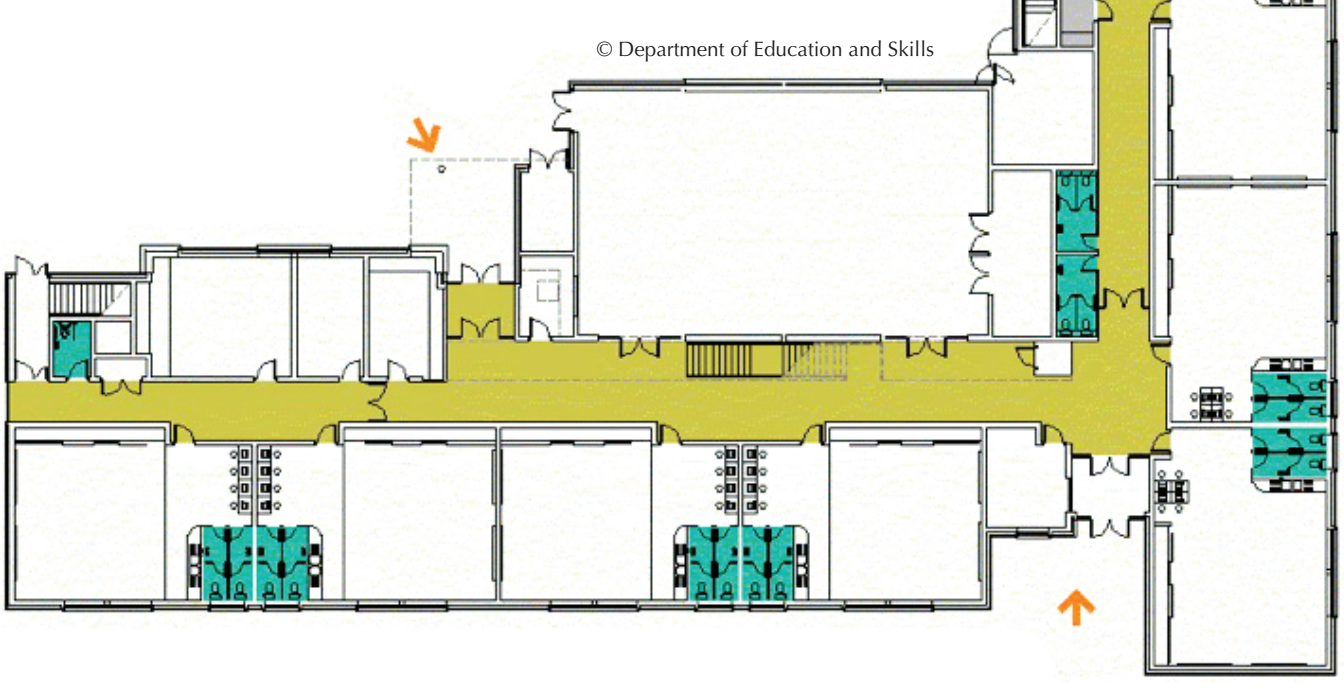




\section{Orientation}

The orientation of a school building has a significant effect on its heating energy use and also has an effect on the usefulness of daylight provided.

The generic school design has been arranged with its classrooms facing both east and south to take advantage of early morning sun. The school hall, plant room, switch room, stores and stairwells have been placed on the north and west sides of the building as these rooms operate at a lower temperature and will provide a buffer space for the rest of the building.
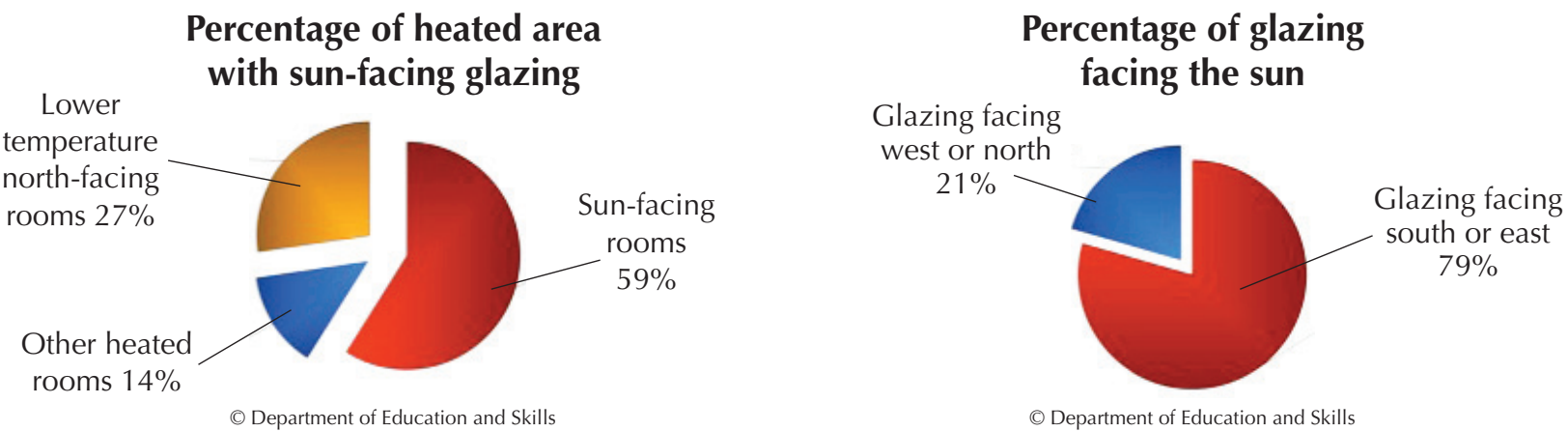

\section{Entrances}

Schools are one of the main public buildings in communities; this consideration prompted the need for clear way-finding to the main entrance. Maintaining a prominent entrance resulted in two slight variations of the design, with main entrances to the north or south, to ensure that the passive solar orientation can still be optimised on almost any site. Once a site is selected, a single main entry should also be determined in order to give a sense of welcome and arrival.

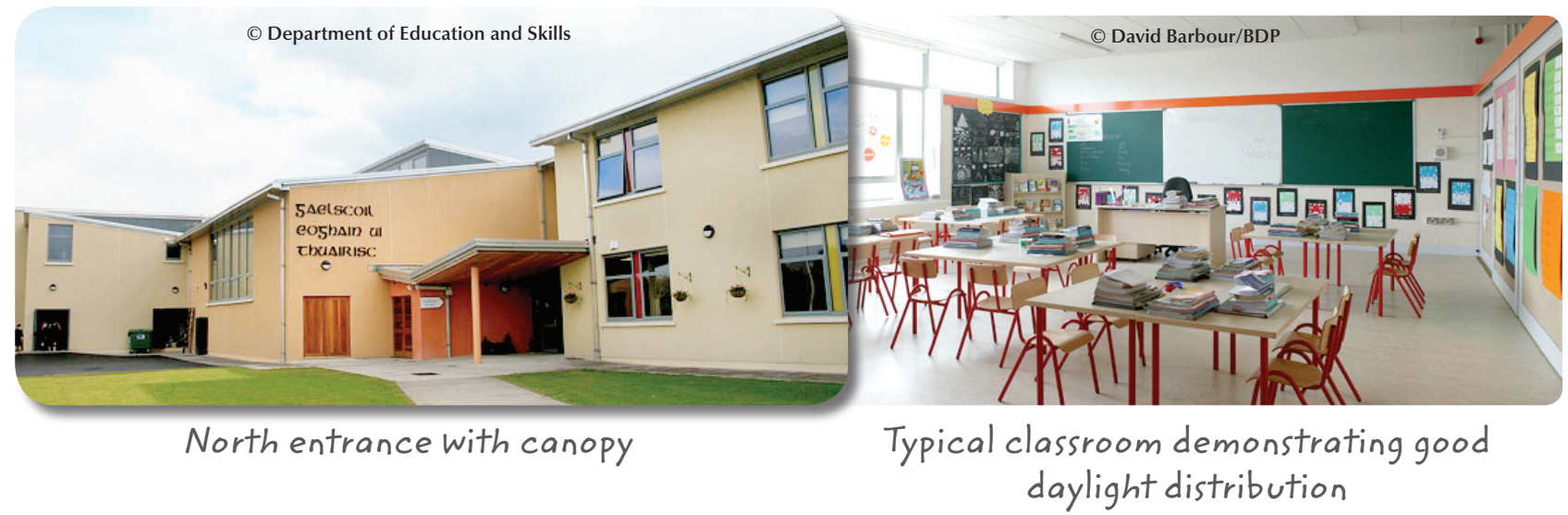

\section{DAYLIGHT}

\section{A typical classroom}

The graphic below (typical classroom plan) indicates the results of the daylight analysis for a typical classroom. Classroom depths and glazing areas were optimised to provide a quality daylight distribution. The results indicate the average daylight factor is 5.2\% over the task area. These confirm that the classrooms are provided with excellent levels of daylight. The high-level windows in particular give a very good distribution of daylight to the rear of the room. This means that it is possible to use the classrooms without additional artificial lighting for $80 \%$ of the working hours of $9.00 \mathrm{am}$ to $3.00 \mathrm{pm}$, throughout the school year. 


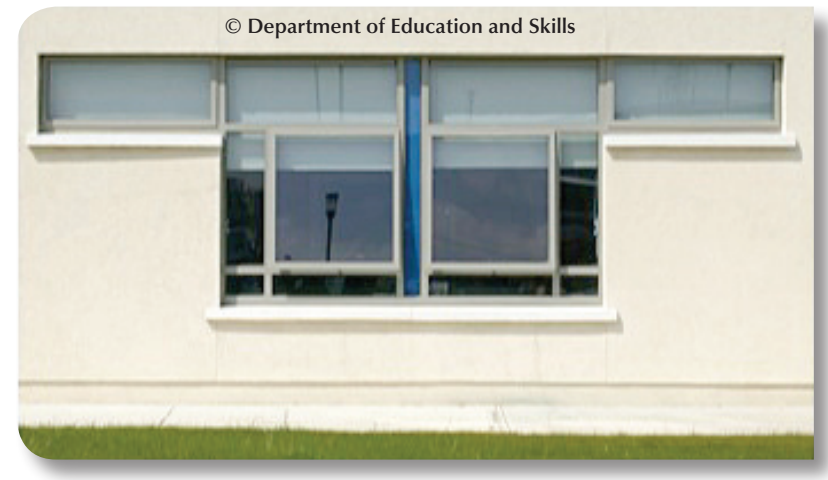

Typical classroom windows

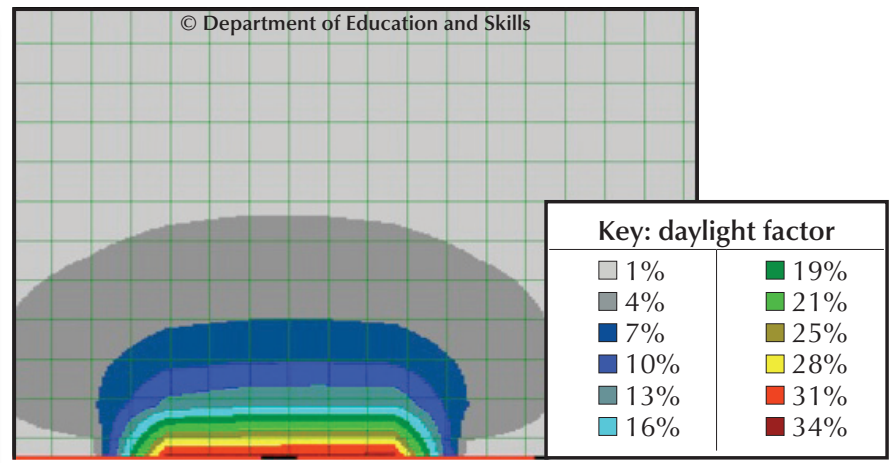

Typical classroom plan, daylight analysis

\section{School hall}

An average daylight factor of $5.4 \%$ was achieved within this space. Balanced distribution is ensured by a north-facing window screen together with a high-level roof lantern at the rear of the space. These duplicate as openable windows to give very good cross-ventilation for this high-occupancy room.

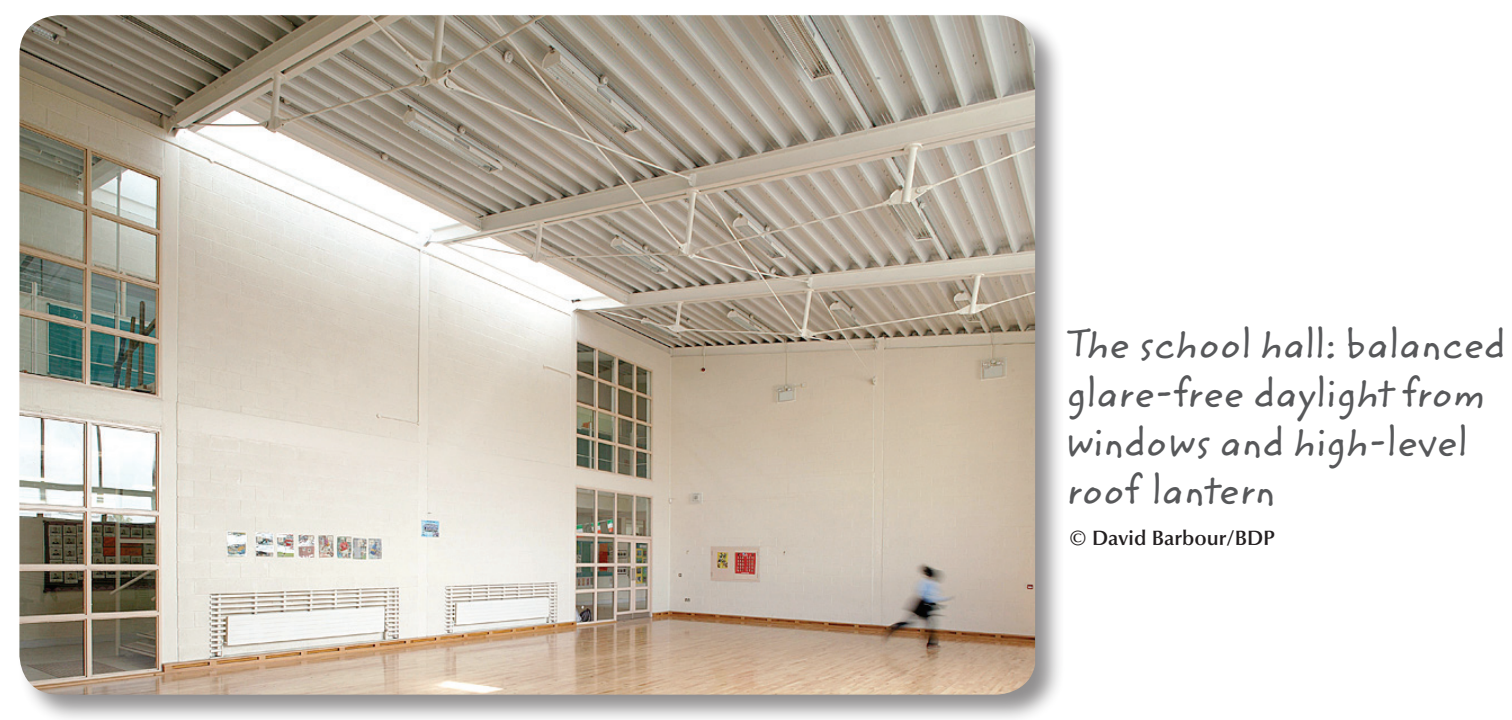

\section{VENTILATION}

\section{Natural ventilation}

All rooms are provided with single-sided natural ventilation with the exception of the school hall, which has cross ventilation by means of additional high-level roof windows. Classroom depths in particular have been minimised in order to maximise ventilation and daylight distribution.

\section{THERMAL PERFORMANCE}

\section{Building form}

The use of a two-storey building, and the relatively tight plan produced by nesting the school hall between the two classroom blocks, results in a relatively low external surface-to-floor area ratio. This relatively low area of exposed external surfaces results in less heat loss through the building fabric. 


\section{Insulation}

By way of ensuring longevity of the basic design, the first GRD schools constructed in 2005-06 were insulated to higher than the required building regulation values at that time. The GRD schools better the requirements of the current 2008 building regulations.

\section{Air leakage}

Careful detailing makes the building more airtight and eliminates unwanted draughts. This reduces the amount of cold air leaking into the building overnight and so less heat is required to bring the school up to a comfortable temperature when the children arrive in the morning.

\section{ENERGY USAGE}

Great care has been taken to optimise the energy performance of every aspect of the school, resulting in a design that uses less than $50 \%$ of the energy used by a school built to good international best practice CIBSE standards. The measured yearly energy usage is: electrical $15 \mathrm{kWh} / \mathrm{m}^{2} / \mathrm{yr}$, heating $42 \mathrm{kWh} / \mathrm{m}^{2} / \mathrm{yr}$, i.e. a total of $57 \mathrm{kWh} / \mathrm{m}^{2} / \mathrm{yr}$.

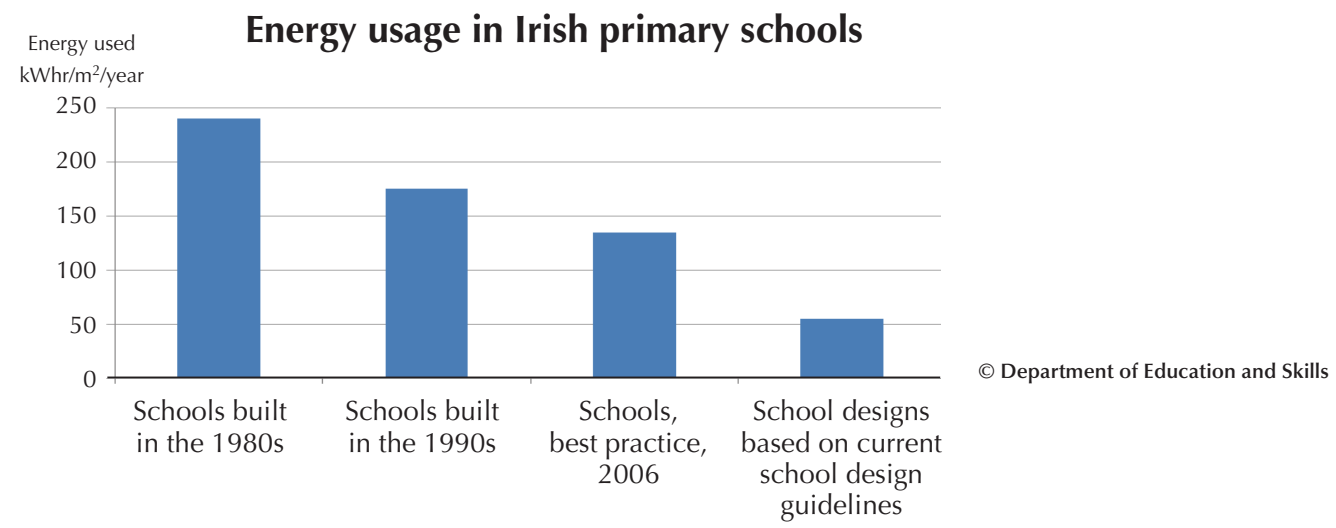

\section{FURTHER DEVELOPMENTS}

\section{Enhancing the design}

To "future proof" the design, and by way of further development, improvements have been made to the building fabric insulation. These are estimated to result in a further improvement in heating energy usage to the order of $20 \%$.

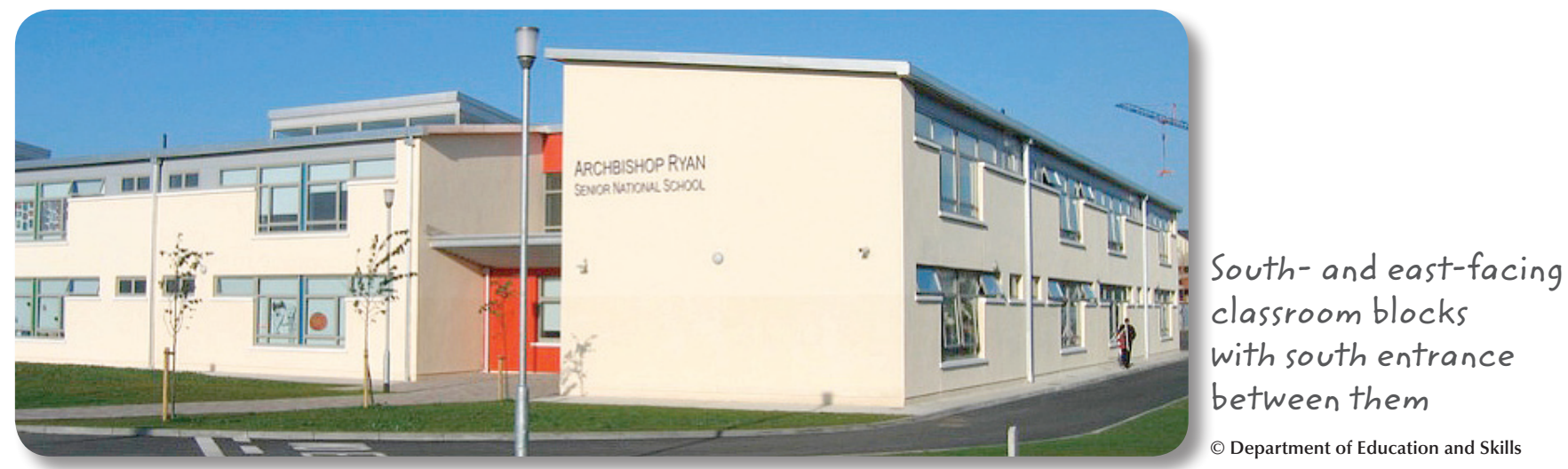




\section{CONCLUSION}

\section{Overall impact and benchmark for the future}

The overall energy impact of the design is considerable as 50 plus schools will be constructed to this proven and optimised low energy design. The total value is approximately EUR $170 \mathrm{~m}$. The first 23 of these schools have already been built with 11 more currently on site.

The generic prototype is considered as the Department's benchmark for design quality of primary schools. As a proven low-energy solution it will drive future research forward closer to zero or carbon neutral buildings. As schools within communities they have a wider educational role in environmental awareness and demonstrate government commitment to a sustainable future.

For more information, contact:

Tony Sheppard

Technical Manager

Planning and Building Unit

Department of Education and Science

Marlborough Street

Dublin 1

Ireland

E-mail: tony_sheppard@education.gov.ie

http://www.education.ie 


\section{ORGANISATION FOR ECONOMIC CO-OPERATION AND DEVELOPMENT}

The OECD is a unique forum where governments work together to address the economic, social and environmental challenges of globalisation. The OECD is also at the forefront of efforts to understand and to help governments respond to new developments and concerns, such as corporate governance, the information economy and the challenges of an ageing population. The Organisation provides a setting where governments can compare policy experiences, seek answers to common problems, identify good practice and work to co-ordinate domestic and international policies.

The OECD member countries are: Australia, Austria, Belgium, Canada, Chile, the Czech Republic, Denmark, Estonia, Finland, France, Germany, Greece, Hungary, Iceland, Ireland, Israel, Italy, Japan, Korea, Luxembourg, Mexico, the Netherlands, New Zealand, Norway, Poland, Portugal, the Slovak Republic, Slovenia, Spain, Sweden, Switzerland, Turkey, the United Kingdom and the United States. The European Commission takes part in the work of the OECD.

OECD Publishing disseminates widely the results of the Organisation's statistics gathering and research on economic, social and environmental issues, as well as the conventions, guidelines and standards agreed by its members.

This work is published on the responsibility of the Secretary-General of the OECD. The opinions expressed and arguments employed herein do not necessarily reflect the official views of the Organisation or of the governments of its member countries. 